\section{DIRECT URINE AMMONIUM \\ MEASUREMENT IN METABOLIC ACIDOSIS: TIME TO MOVE ON}

To the editor: The case report by Tuchscherer and Rehman is indeed interesting. ${ }^{1}$ However, this article requires that we look more closely at what is meant by urinary ammonium being measured. The renal response to metabolic acidosis is to increase excretion of hydrogen ion in the form of ammonium; the measurement of its urinary concentration is important when trying to identify the cause of the acidosis. ${ }^{2}$ Routine urine ammonium measurements are not available in regular diagnostic laboratories as the traditional methods used, such as the formaldehyde titration method, are cumbersome, time consuming, and expensive. As a result, estimation of urinary osmolal gap was advocated as a surrogate marker of urine ammonium excretion. This method overestimates the urine ammonium concentration and does not truly reflect the contribution of the anions accompanying ammonium to the osmolality. To overcome this, "modified urine osmolal gap" "w was suggested. Although this is an improvement over the conventional urine osmolal gap, significant inaccuracies were recognized in the presence of increased concentration of alcohols or during enhanced excretion of polyvalent anions. In addition, it does not reflect small changes in urine ammoniumexcretion. ${ }^{4}$

It is likely that a routine enzymatic method used in clinical laboratories for measuring serum ammonium could easily be adapted to estimate urinary ammonium. ${ }^{5}$ One may argue that it is not possible as urine ammonium concentrations are approximately 1,000-fold higher than serum concentrations during metabolic acidosis. This can easily be managed with predilution of the urine. If a clinical laboratory is equipped with an autoanalyzer, then no more specific instruments or reagents are required. What would be required would be to dilute the sample of urine and follow the normal procedure used to measure serum ammonium. Ha and colleagues measured urine ammonium level with two different modern autoanalyzers by simple modification of the regular serum ammonium analyzer. ${ }^{6}$ Interestingly, Katagawa and colleagues compared the accuracy of this method to the formaldehyde titration method and found good agreement.? In our hospital, we directly measure urine ammonium levels by enzymatic assay using glutamate dehydrogenase with predilution of the urine by 1:200 in a regular serum ammonium analyzer. The advantages are simple, fast, accurate, and economical results. Before making a recommendation that this become a routine approach, we suggest that further comparative studies be made at different centers to corroborate our observations and provide external validation.

A word of caution to close: such a process will require transport of freshly collected urine specimens to minimize any impact of bacterial growth; the other option would be to ensure rapid refrigeration to retard bacterial growth. Bacteria can degrade urea and lead to (false) elevations in urine ammonium.

\section{Subramanian Senthilkumaran, MD} Department of Emergency and Critical Care, Sri Gokulam Hospitals and Research Institute, Salem, Tamil Nadu, India

\section{Narendra Nath Jena, MBBS}

Department of Emergency Medicine, Meenakshi Mission Hospital \& Research Centre, Madurai, India Srinivasan Jayaraman, MD

Department of Emergency Medicine, Hamad General Hospital, Doha, Qatar

\section{Ritesh G. Menezes, MD}

Department of Forensic Medicine \& Toxicology, ESIC-Medical College \& PGIMSR, Bangalore, India

Ponniah Thirumalaikolundusubramanian, $M D$

Department of Internal Medicine, Chennai Medical College Hospital and Research Center, Irungalur, Trichy, Tamil Nadu, India

\section{References}

1. Tuchscherer J, Rehman H. Metabolic acidosis in toluene sniffing. CFEM 2013; 15:249-52.

2. Halperin ML, Richardson RMA, Bear RA, et al. Urine ammonium: the key to the diagnosis of distal renal tubular acidosis. Nephron 1988;50:1-4, doi:10.1159/000185107.

3. Dyck RF, Asthana S, Kalra J, et al. A modification of the urine osmolal gap: an improved method for estimating urine ammonium. Am 7 Nephrol 1990; 10:359-62, doi:10.1159/000168150.

4. Meregalli P, Lüthy C, Oetliker $\mathrm{OH}$, Bianchetti MG. Modified urine osmolal gap: an accurate method for estimating the urinary ammonium concentration? Nephron 1995;69:98-101, doi:10.1159/ 000188374.

5. Kraut JA, Madias NE. Differential diagnosis of non gap metabolic acidosis: value of a systematic approach. Clin 7 Am Soc Nephrol 2012;7:671-9, doi:10. 2215/CJN.09450911.

6. $\mathrm{Ha}$ LY, Chiu WW, Davidson JS. Direct urine ammonium measurement: time to discard urine anion and osmolar gaps. Ann Clin Biochem 2012;49: 606-8, doi:10.1258/acb.2012.012013.

7. Katagawa K, Nagashima T, Inase N, et al. Urinary ammonium measurement by the auto-analyzer method. Kidney Int 1989;36: 291-4, doi:10.1038/ki.1989.193. 